\title{
Bipolar Disorder and Its Comorbidities: How to Treat Since the Gold Standard for One Disease Can Worsen the Other?
}

\author{
Andrea Amerio ${ }^{1,2} \bowtie$ \\ ${ }^{1}$ Inpatient Mental Health Service, SS. Antonio e Biagio e Cesare Arrigo Hospital, Alessandria, Italy \\ ${ }^{2}$ Mood Disorders Program, Tufts Medical Center, Boston, MA, USA
}

\section{To the Editor,}

Psychiatric comorbidity is extremely common in bipolar disorder (BD). More than half of $\mathrm{BD}$ patients have an additional diagnosis, one of the most difficult to manage being obsessivecompulsive disorder (OCD).

The majority of BD-OCD patients experienced the onset of $\mathrm{OCD}$ prior to the onset of $\mathrm{BD}$ and presented higher prevalence of family history for mood disorders versus non-BDOCD patients. ${ }^{1,2}$ Moreover, comorbid BD and OCD cycled together, with OC symptoms often remitting during manic/ hypomanic episodes. ${ }^{3}$

Treating BD-OCD patients remains a great challenge. Though serotonin reuptake inhibitors (SRIs) are the first line treatment for OCD, they can induce mood instability in BD, especially if administered at high doses and maintained for a long time.

We present the case of a severe BD-OCD patient who experienced complete remission with aripiprazole augmentation to mood stabilizer.

The patient is a 22-year-old Caucasian unmarried woman with positive family history for major depressive disorder. From the age of 16 , she had presented fear of contamination, washing and cleaning rituals that had partially impaired her functional capacity. These symptoms met Diagnostic and Statistical Manual of Mental Disorders-fifth Edition (DSM-5) criteria for OCD and were untreated for four years. No history of manic or depressive episodes was reported.

At the age of 20 the obsessions and compulsions increased and she presented with depressed mood and feelings of worth-

\footnotetext{
Received: February 26, 2019 Revised: May 19, 2019

Accepted: July 17, 2019

$\square$ Correspondence: Andrea Amerio, MD, PhD

Inpatient Mental Health Service, SS. Antonio e Biagio e Cesare Arrigo Hospital, Via Venezia 16, Alessandria (AL) 15121, Italy

Tel: +39-0131-206410, Fax: +39-0131-206101

E-mail: andrea.amerio@ospedale.al.it

(c) This is an Open Access article distributed under the terms of the Creative Commons Attribution Non-Commercial License (https://creativecommons.org/licenses/bync/4.0) which permits unrestricted non-commercial use, distribution, and reproduction in any medium, provided the original work is properly cited.
}

lessness. She was admitted to the inpatient service and treated with fluoxetine $40 \mathrm{mg} /$ day; obsessive-compulsive and affective symptoms were well controlled and satisfactory quality of life was regained.

After three months on fluoxetine $40 \mathrm{mg} /$ day, she developed a manic episode. Her therapy was modified to lithium carbonate $900 \mathrm{mg} / \mathrm{day}$ (serum level achieved, $0.8-0.9 \mathrm{mEq} / \mathrm{L}$ ) and olanzapine $20 \mathrm{mg} /$ day. Olanzapine was gradually decreased and lithium carbonate was continued with only partial remission of obsessive-compulsive symptoms and mood stabilization.

After six months, intrusive and persistent thoughts and compulsive rituals increased prominently. Aripiprazole $10 \mathrm{mg} /$ day was added to lithium carbonate and complete remission of bipolar and obsessive-compulsive symptoms for the following twelve months was reported.

Aripiprazole is the first approved atypical antipsychotic with a mechanism of action that exerts a partial agonism with high affinity at Dopamin $\mathrm{D}_{2}$ and Serotonin-5- $\mathrm{HT} 1_{\mathrm{A}}$ receptors as well as an antagonism at Serotonin-5-HT2 $2_{\mathrm{A}}$ receptors. Its peculiar pharmacodynamic profile might support a favorable influence on negative symptoms and cognitive dysfunctions in schizophrenic patients, managing acute mania and stabilization phases in $\mathrm{BD}$, and in addition to SRIs in refractory OCD. ${ }^{4}$ This case report describes the efficacy of aripiprazole augmentation to lithium carbonate also as maintenance therapy in BD-OCD.

The DSM explicitly produces overlapping clinical criteria for many diagnoses, especially mood and anxiety disorders, guaranteeing comorbidity in quite a different sense than in the medical meaning of the term as co-occurrence of independent diseases. Using DSM definition, it is unclear whether concomitant diagnoses actually reflect the presence of distinct clinical entities or refer to multiple manifestations of a single clinical entity.

On the contrary, in the hierarchical approach, advocated in classic European psychopathology, anxiety presentations, like OCD, are not diagnosed as separate conditions when co-occurring with mood presentations, like BD. In other words, $\mathrm{OCD}$ 
was not diagnosed unless $\mathrm{BD}$ was ruled out. If correct, as seems to be the case based on the available literature, OCD patients should be evaluated about family history for mood disorders and other evidence of bipolarity.

If most OCD symptoms are secondary to $\mathrm{BD}$, then it may be that both groups of symptoms may respond to adequate mood stabilizer treatment. ${ }^{5}$ Due to the risk of switching to mania in patients treated with SRIs, aripiprazole augmentation to mood stabilizers can be consider as an alternative treatment strategy in treatment-resistance comorbid patients. Addition of SRIs may be needed only in a minority of BD patients with refractory OCD. Benefit with other antipsychotics was also seen, although a few reports also exist of exacerbation of OC symptoms with neuroleptic agents.

To allow more definitive conclusions, prospective controlled studies are needed in this important diagnostic and clinical topic.

\section{Conflicts of Interest}

The author has no potential conflicts of interest to disclose.
ORCID iD

Andrea Amerio

https://orcid.org/0000-0002-3439-340X

\section{REFERENCES}

1. Tonna M, Amerio A, Odone A, Stubbs B, Ghaemi SN. Comorbid bipolar disorder and obsessive-compulsive disorder: which came first? Aust N Z J Psychiatry 2016;50:695-698.

2. Amerio A, Tonna M, Odone A, Stubbs B, Ghaemi SN. Heredity in comorbid bipolar disorder and obsessive-compulsive disorder patients. Shanghai Arch Psychiatry 2015;27:307-310.

3. Amerio A, Tonna M, Odone A, Stubbs B, Ghaemi SN. Course of illness in comorbid bipolar disorder and obsessive-compulsive disorder patients. Asian J Psychiatr 2016;20:12-14.

4. Centorrino F, Fogarty KV, Cimbolli P, Salvatore P, Thompson TA, Sani G, et al. Aripiprazole: initial clinical experience with 142 hospitalized psychiatric patients. J Psychiatr Pract 2005;11:241-247.

5. Mucci F, Toni C, Favaretto E, Vannucchi G, Marazziti D, Perugi G. Obsessive-compulsive disorder with comorbid bipolar disorders: clinical features and treatment implications. Curr Med Chem 2018;25: 5722-5730. 